\title{
JL1 Antigen Expression on Bone Marrow Lymphoma Cells from Patients With Non-Hodgkin Lymphoma
}

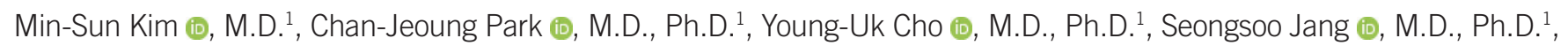

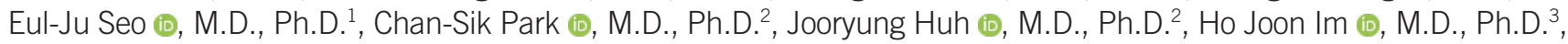

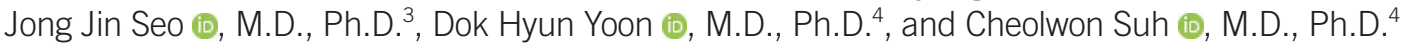

Departments of ${ }^{1}$ Laboratory Medicine, ${ }^{2}$ Pathology, ${ }^{3}$ Pediatrics, and ${ }^{4}$ Oncology, Asan Medical Center and University of Ulsan College of Medicine, Seoul, Korea

Background: JL1, a CD43 epitope and mucin family cell surface glycoprotein, is expressed on leukemic cells. An anti-JL1 antibody combined with a toxic substance can have targeted therapeutic effects against JL1-positive leukemia; however, JL1 expression on bone marrow (BM) lymphoma cells has not been assessed using flow cytometry. We investigated JL1 expression on BM lymphoma cells from patients with non-Hodgkin lymphoma $(\mathrm{NHL})$ to assess the potential of JL1 as a therapeutic target.

Methods: Patients with BM involvement of mature B-cell $(\mathrm{N}=44)$ or $\mathrm{T}$ - and natural killer (NK)-cell $(N=4)$ lymphomas were enrolled from May 2015 to September 2016. JL1 expression on BM lymphoma cells was investigated using flow cytometry. Clinical, pathologi$\mathrm{cal}$, and cytogenetic characteristics, and treatment responses were compared according to JL1 expression status.

Results: Of the patients with NHL and BM involvement, 37.5\% (18/48) were JL1-positive. Among mature B-cell lymphomas, 100\%, 38.9\%, 33.3\%, 100\%, and 25.0\% of Burkitt lymphomas, diffuse large B-cell leukemias, mantle cell leukemias, Waldenstrom macroglobulinemia, and other B-cell lymphomas, respectively, were JL1-positive. Three mature T- and NK-cell NHLs were JL1-positive. JL1 expression was associated with age $(P=0.045)$, complete response $(P=0.004)$, and BM involvement at follow-up $(P=0.017)$, but not with sex, performance status, the B symptoms, packed marrow pattern, cytogenetic abnormalities, or survival.

Conclusions: JL1 positivity was associated with superior complete response and less BM involvement in $\mathrm{NHL}$ following chemotherapy.

Key Words: JL1 expression, Flow cytometry, Mature B-cell lymphoma, T- and natural killercell lymphoma
Received: December 4, 2018

Revision received: March 16, 2019

Accepted: July 26, 2019

Corresponding author: Chan-Jeoung Park, M.D., Ph.D.

University of Ulsan College of Medicine and Asan Medical Center, 88 Olympic-ro 43-gil,

Songpa-gu, Seoul 05505, Korea

Tel: $+82-2-3010-4508$

Fax: +82-2-478-0884

E-mail: cjpark@amc.seoul.kr

\section{(i) 5}

C) Korean Society for Laboratory Medicine This is an Open Access article distributed under the terms of the Creative Commons Attribution Non-Commercial License (http://creativecommons.org/licenses/by-nc/4.0) which permits unrestricted non-commercial use, distribution, and reproduction in any medium, provided the original work is properly cited.

\section{INTRODUCTION}

JL1 is a CD43 epitope and cell surface glycoprotein of the mucin family that is expressed on Stage II double-positive (CD4 ${ }^{+}$ $\mathrm{CD}^{+}$) human cortical thymocytes [1-3]. JL1 is also expressed on hematopoietic cells at specific stages of differentiation, including early stage lymphoid precursors and late stage myeloid cells [2-6]. Subsequently, JL1 was detected on CD34+ CD10 lymphoid precursors and some immature myeloid cells in bone marrow (BM) [2, 7]. Although JL1 expression is restricted to specific populations of thymocytes and BM cells, it is also expressed in approximately $60 \%$ of acute leukemias, regardless of lineage [7]. Moreover, JL1 is significantly expressed in adult and childhood acute leukemias [2, 8] and on BM hematopoietic pre- 
cursor cells [4, 7, 9]; however, JL1 expression on BM lymphoma cells has not been assessed using flow cytometry. An anti-JL1 antibody combined with a toxic substance targeting JL1-positive leukemia has a therapeutic effect [10]. Hwang, et al. [11] assayed JL1 expression by immunohistochemistry (IHC) in Burkitt lymphoma and other lymphomas and found that it was significantly correlated with the survival of patients with Burkitt lymphoma.

We investigated JL1 expression on BM lymphoma cells in patients with non-Hodgkin lymphoma (NHL) and BM involvement to assess the potential of JL1 as a therapeutic target.

\section{METHODS}

Patients, treatment, and response evaluation

A total of 48 patients with BM involvement of mature B-cell or Tand natural killer (NK)-cell lymphoma were enrolled at Asan Medical Center, Seoul, Korea, from May 2015 to September 2016. Lymphoma was diagnosed by lymph node biopsy, according to the 2016 WHO classification of lymphoid neoplasms [12]. BM involvement in $\mathrm{NHL}$ was diagnosed based on a combination of cell morphology on BM aspirate smears, clot sections, biopsies, and IHC for CD20, CD79a, CD3, CD4, CD8, CD56, and CD34. Flow cytometry was conducted for JL1, CD2, CD3, cytoplasmic CD3, CD5, CD7, CD10, CD20, kappa, lambda, CD22, CD23, CD45, CD56, FMC7, and terminal deoxynucleotidyl transferase.

Performance status was evaluated according to the Eastern Cooperative Oncology Group (ECOG) criteria [13]. The ECOG criteria assess how the disease affects the daily living abilities of the patient.

Among 48 patients, two died before treatment, and five refused chemotherapy; hence, 41 received chemotherapy based on the National Comprehensive Cancer Network (NCCN) clinical practice guidelines [14-17]. Standard front-line chemotherapy for mature B-cell lymphoma and mature T- and NK-cell lymphoma included rituximab with cyclophosphamide, doxorubicin, vincristine, and prednisone (R-CHOP); CHOP alone; rituximab plus cyclophosphamide, vincristine, and prednisone (R-CVP); or rituximab alone. Treatment response was assessed based on the NCCN guidelines [16, 17]. The median patient follow-up duration was 12 (range: 1-29) months. This study was conducted in accordance with the Declaration of Helsinki (2013 revision). Written informed consent and approval by an Institutional Review Board were exempted because the assessment of JL1 expression was included in the routine immunophenotyping of BM aspirates. Clinical, pathological, and cytogenetic characteristics of the patients were obtained from electronic medical records.

\section{Flow cytometry}

BM aspirates and biopsies were collected from the posterior iliac crests of patients with NHL. Flow cytometric analysis of JL1 expression on lymphoma cells in BM aspirates (EDTA) was conducted using a FACSCanto II flow cytometer (Becton Dickinson, Sunnyvale, CA, USA). CD19- fluorescein isothiocyanate (FITC), JL1- Phycoerythrin (PE), and CD45- allophycocyanin (APC) were used to measure JL1 expression on B-lymphoma cells. Panels of CD7-FITC/JL1-PE/CD3-Peridinin chlorophyll protein
A

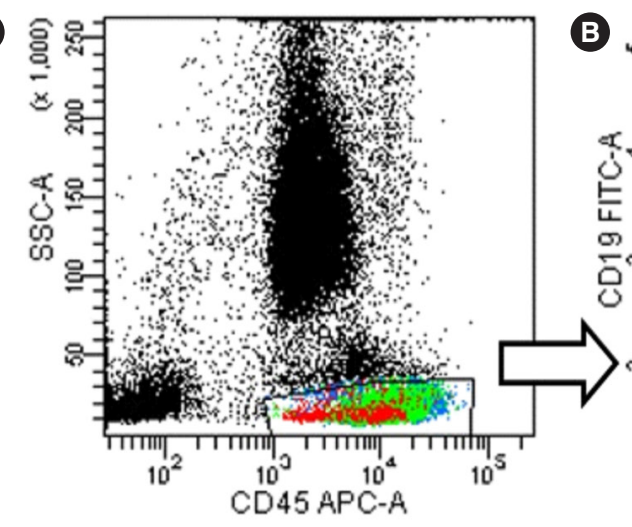

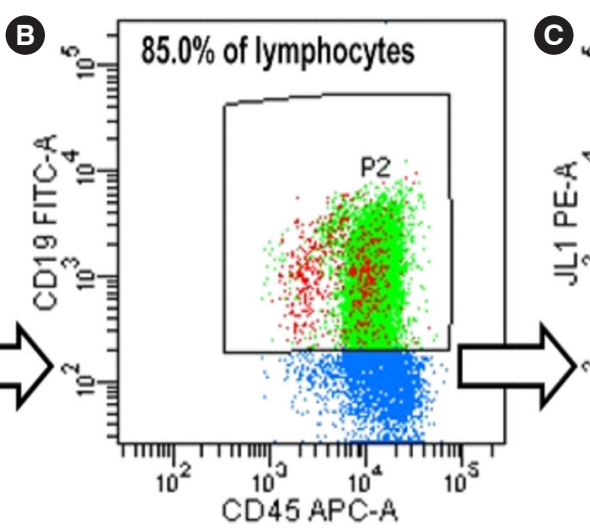

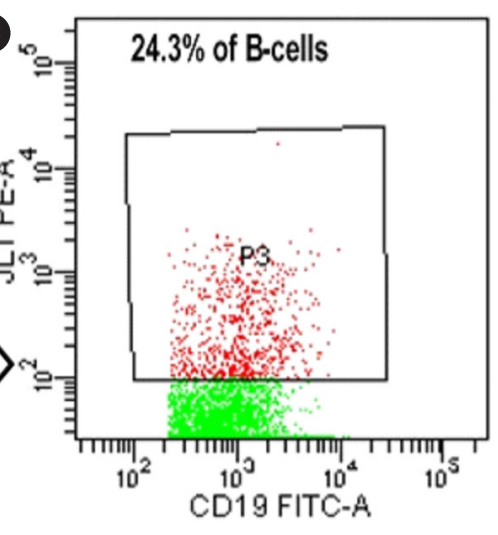

Fig. 1. Measurement of JL1 expression on lymphoma cells by flow cytometry in a patient with follicular lymphoma and bone marrow involvement. Mononuclear lymphoma cells were isolated by gating intermediate to bright CD45-APC expression and low SSC (A), CD19+ Blymphoma cells were isolated by gating intermediate to bright CD45-APC and positive CD19-FITC stained cells (B), and the proportion of JL1-expressing lymphoma cells among B-lymphoma cells was calculated using a CD19-FITC vs JL1-PE dot plot (C). The results of JL1 expression analysis are presented as the proportion of JL1-positive cells among gated lymphoma cells (24.3\% in this case). Abbreviations: CD, cluster of differentiation; SSC, side scatter; FSC, forward scatter; PE, phycoerythrin; APC, allophycocyanin. 
(PerCP)/CD45-APC, CD4-FITC/JL1-PE/CD3-PerCP/CD45-APC, or CD56-FITC/JL1-PE/CD3-PerCP/CD45-APC were used to measure JL1 expression on lymphoma cells according to the T- or NK-cell type of the original lymphoma.

Nucleated cells ( $\geq 50,000$ per tube) were acquired, and Blymphoma cells were isolated by gating intermediate to bright CD45 expression and low side-scatter (SSC), followed by isolation of $\mathrm{CD} 19^{+} \mathrm{B}$-lymphoma cells by gating positive $\mathrm{CD} 19^{+}$from intermediate to bright $\mathrm{CD} 45^{+}$cells. The proportion of B-lymphoma cells expressing JL1 was calculated using JL1 vs CD19 dot plots (Fig. 1). T-lymphoid cells were isolated by gating intermediate to bright CD45 expression and low SSC, based on $\mathrm{CD}^{+}$or $\mathrm{CD}^{+}$ and surface $\mathrm{CD}^{-}$or $\mathrm{CD}^{+}$from the original T-cell lymphoma immunophenotyping, using the CD4 or CD7 vs CD3 dot plots. The proportion of $\mathrm{JL}^{+}$lymphoma cells among the re-gated $\mathrm{T}$ lymphoid cells was calculated using the JL1 vs CD4 or CD7 dot plots. NK-lymphoma cells were isolated from the population gated on intermediate to bright expression of CD45 and low SSC and re-gated for $\mathrm{CD}^{2} 6^{+} \mathrm{CD}^{-}$NK-lymphoma cells based on the CD56 vs CD3 dot plots. The proportion of JL1-expressing lymphoma cells among the re-gated NK-lymphoma cells was calculated based on the JL1 vs CD56 dot plots. The JL1 expression results are presented as the proportion of JL1-positive cells among lymphoma cells (Fig. 1).

Specimens were considered JL1-positive when it was detected on $\geq 20 \%$ of lymphoma cells. All antibodies, except for CD45 (Becton Dickinson) and JL1 (Dinona Inc., Seoul, Korea), were obtained from Beckman Coulter (Miami, FL, USA).

\section{Statistical analysis}

Relationships between JL1 expression and clinical, pathological, and cytogenetic characteristics were evaluated using the $\chi^{2}$ or Fisher's exact tests. The data were summarized as count (percentage) or median (range). Overall survival (OS) rates were estimated using the Kaplan-Meier method. OS was defined as the time from diagnosis to death from any cause. $P<0.05$ was considered statistically significant. SPSS version 22.0 for Windows (IBM Corp., Armonk, NY, USA) was used for statistical analyses.

\section{RESULTS}

\section{Patient characteristics and treatment responses}

The clinical and laboratory characteristics of the 48 patients with $\mathrm{NHL}$ and BM involvement are presented in Table 1. Of the patients with NHL, 44/48 (91.7\%) had mature B-cell and 4/48 (8.3\%) had T- and NK-cell lymphomas. The most common sub-
Table 1. Clinical and laboratory characteristics of $48 \mathrm{NHL}$ patients with BM involvement

\begin{tabular}{|c|c|}
\hline Characteristics & $\mathrm{N}$ \\
\hline Sex, M:F & $31: 17$ \\
\hline Age (yr), median (range) & $59.5(5-84)$ \\
\hline \multicolumn{2}{|l|}{ NHL subtype } \\
\hline Mature B-cell neoplasms & 44 \\
\hline Diffuse large B-cell lymphoma & 18 \\
\hline Follicular lymphoma & 7 \\
\hline Mantle cell lymphoma & 6 \\
\hline Burkitt lymphoma & 4 \\
\hline Nodal marginal zone lymphoma & 2 \\
\hline Pro-lymphocytic leukemia & 1 \\
\hline Chronic lymphocytic leukemia & 1 \\
\hline Waldenstrom macroglobulinemia & 1 \\
\hline Other B-cell lineage lymphoma & 4 \\
\hline Mature T- and NK-cell neoplasms & 4 \\
\hline Aggressive NK-cell leukemia & 1 \\
\hline $\begin{array}{l}\text { Systemic Epstein-Barr virus-positive pediatric T-cell } \\
\text { lymphoproliferative disease }\end{array}$ & 1 \\
\hline Peripheral T-cell lymphoma, NOS & 1 \\
\hline Angioimmunoblastic T-cell lymphoma & 1 \\
\hline \multicolumn{2}{|l|}{ ECOG performance status* } \\
\hline 0 & 5 \\
\hline 1 & 14 \\
\hline 2 & 16 \\
\hline 3 & 7 \\
\hline 4 & 1 \\
\hline B symptoms & 21 \\
\hline Packed marrow pattern & 18 \\
\hline Cytogenetic abnormalities & 28 \\
\hline Complete response $^{\dagger}$ & 22 \\
\hline BM involvement at follow-up & 11 \\
\hline Relapse & 0 \\
\hline Survival ${ }^{\ddagger}$ & 30 \\
\hline Death $^{\ddagger}$ & 18 \\
\hline
\end{tabular}

*Performance status could not be evaluated in five patients at initial diagnosis; 'The 41 patients received combination chemotherapy based on NCCN practice guidelines [16]; ${ }^{\ddagger}$ Two years after diagnosis of NHL.

Abbreviations: M, male; F, female; NK, natural killer; NOS, not otherwise specified; NCCN, National Comprehensive Cancer Network; NHL, non-Hodgkin lymphoma; ECOG, Eastern Cooperative Oncology Group; BM, bone marrow.

types were diffuse large B-cell lymphoma (DLBCL; 18/48, 37.5\%), follicular lymphoma (FL; 7/48, 14.6\%), mantle cell lymphoma (MCL; 6/48, 12.5\%), Burkitt lymphoma (4/48, 8.3\%), and nodal 
marginal zone lymphoma (MZL; 2/48, 4.2\%). The ECOG performance status values were $0-2$ in 35/48 (72.9\%) patients, while $22 / 41(53.6 \%)$ achieved complete response (CR) following chemotherapy (Table 1).

Of the 41 patients who received combination chemotherapy, 22 (53.6\%) patients achieved CR. A total of 12/48 (25.0\%) patients died from septic shock or pneumonia $(N=6)$, respiratory failure $(N=2)$, multi-organ failure $(N=1)$, or unknown causes $(\mathrm{N}=3)$.

Table 2. Comparisons between JL1-positive and JL1-negative status among $48 \mathrm{NHL}$ patients with $\mathrm{BM}$ involvement

\begin{tabular}{|c|c|c|c|}
\hline & \multicolumn{2}{|c|}{ JL1 status } & \multirow[b]{2}{*}{$P$} \\
\hline & $\begin{array}{l}\text { Positive } \\
(\mathrm{N}=18)\end{array}$ & $\begin{array}{c}\text { Negative } \\
(\mathrm{N}=30)\end{array}$ & \\
\hline Age (yr), median (range) & $57(5-77)$ & $63(29-82)$ & 0.045 \\
\hline Sex & & & 0.815 \\
\hline Male & 12 & 19 & \\
\hline Female & 6 & 11 & \\
\hline NHL subtype & & & 0.106 \\
\hline Mature B-cell neoplasms & 15 & 29 & \\
\hline Burkitt lymphomas & 4 & 0 & \\
\hline DLBCL & 7 & 11 & \\
\hline $\mathrm{MCL}$ & 2 & 4 & \\
\hline Waldenstrom macroglobulinemia & 1 & 0 & \\
\hline Other B-cell lineage lymphoma & 1 & 3 & \\
\hline Follicular lymphoma & 0 & 7 & \\
\hline Nodal marginal zone lymphoma & 0 & 2 & \\
\hline Pro-lymphocytic leukemia & 0 & 1 & \\
\hline Chronic lymphocytic leukemia & 0 & 1 & \\
\hline Mature T- and NK-cell neoplasms & 3 & 1 & \\
\hline ECOG performance status & & & 0.933 \\
\hline $0,1,2$ & 13 & 22 & \\
\hline 3,4 & 5 & 8 & \\
\hline B symptoms & 11 & 10 & 0.074 \\
\hline Packed marrow pattern & 4 & 14 & 0.090 \\
\hline Cytogenetic abnormalities* & 8 & 20 & 0.131 \\
\hline Complete response & 13 & 9 & 0.004 \\
\hline BM involvement at follow-up & 2 & 9 & 0.017 \\
\hline Survival & 12 & 18 & 0.557 \\
\hline
\end{tabular}

*Twenty-two patients had complex karyotypes, and t(14;18), +11, del(6), dup(1), inv(7), add(8), and dup(1) were observed, respectively, in seven patients.

Abbreviations: NHL, non-Hodgkin lymphoma; NK, natural killer; ECOG, Eastern Cooperative Oncology Group; BM, bone marrow.
Comparison of clinical, pathological, and cytogenetic characteristics according to JL1 expression status

Eighteen NHL patients with BM involvement were JL1-positive (18/48, 37.5\%). Mature B-cell NHL (15/44, 34.1\%) showed a tendency towards lower expression of JL1 than T- and NK-cell $\mathrm{NHL}$ (3/4, 75.0\%); however, the difference was not statistically significant $(P=0.106)$. Among mature $B$-cell lymphomas, $4 / 4$ (100\%) Burkitt lymphomas, 7/18 (38.9\%) DLBCLs, 2/6 (33.3\%) MCLs, 1/1 (100\%) Waldenstrom macroglobulinemia, and 1/4 (25.0\%) other B-cell lymphoma were JL1-positive. Of the four Tand NK-cell lymphomas, three were JL1-positive, and one angioimmunoblastic lymphoma was JL-1 negative (Table 2).

The median percentage of lymphoma cells in BM aspirates from the $48 \mathrm{BM}$ involved NHL patients was $28.2 \%$ (range: 6.4 92.0\%). In the JL1-positive BM lymphoma specimens ( $N=18$ ), the median percentage of JL1-positive lymphoma cells was 37.5\% (range: 16.4-94.1\%), with median values of $41.2 \%$ in mature B-cell NHL and 36.0\% in T- and NK-cell lymphoma. In Burkitt lymphoma, which had the highest proportion of JL1-positive lymphoma cells, the median percentage of JL1-positive lymphoma cells was $60.5 \%$ (range: $41.2-94.1 \%$ ) (Table 3 ).

Follow-up BM investigations were performed after chemotherapy in 27 patients. Of these 27 patients, 2/11 (18.2\%) who were initially JL1-positive and 9/16 (56.3\%) who were initially JL1-negative had BM involvement at follow-up $(P=0.017)$.

JL1 expression in NHL was associated with age $(P=0.045)$, $\mathrm{CR}(P=0.004)$, and $\mathrm{BM}$ involvement at follow-up $(P=0.017)$; however, no other characteristics, including sex, performance status, presence of B symptoms (fever, night sweat, weight loss), packed marrow pattern, cytogenetic abnormalities, and survival, were associated with JL1 status. Kaplan-Meier analysis showed

Table 3. Flow cytometric measurement of JL1-positive lymphoma cells among BM aspirates in the patients with NHL and BM involvement

\begin{tabular}{lcl}
\hline & N & \multicolumn{1}{c}{ Median (range) } \\
\hline JL1-positive lymphoma cells & 18 & $37.5 \%(16.4-94.1 \%)$ \\
Mature B-cell NHL & 15 & $41.2 \%(21.5-94.1 \%)$ \\
Burkitt lymphoma & 4 & $60.5 \%(41.2-94.1 \%)$ \\
DLBCL & 7 & $41.9 \%(24.3-61.3 \%)$ \\
MCL & 2 & $46.7 \%(33.0-60.4 \%)$ \\
Waldenstrom macroglobulinemia & 1 & $32.8 \%(-)$ \\
Other B-cell lineage lymphoma & 1 & $37.6 \%(-)$ \\
T- and NK-cell lymphoma & 3 & $36.0 \%(16.4-75.4 \%)$ \\
\hline
\end{tabular}

Abbreviations: DLBCL, diffuse large B-cell lymphoma; $M C L$, mantle cell lymphoma; NK, natural killer; NHL, non-Hodgkin lymphoma; BM, bone marrow. 
that OS did not differ significantly between patients with and without JL1 expression (mean survival time was 11 vs 15 months, respectively; $P=0.557$ ).

\section{DISCUSSION}

We showed 100\% (4/4 patients) JL1-positivity by flow cytometry in BM aspirates of Burkitt lymphoma, as well as variable JL1positivity in other NHL subtypes. Hwang, et al. [11] reported that JL1-positivity by IHC in lymph nodes of Burkitt lymphoma was 30.2\% (16/53 patients) and that JL1-positivity was not observed in DLBCL, FL, MCL and MZL specimens. The difference in JL1-positivity between the results of Hwang, et al. [11] and ours is most likely due to the different methods used (IHC vs flow cytometry), criteria for JL1-positivity (>50\% vs $>20 \%$ ), and specimens (lymph nodes vs BM aspirates). The concordance between flow cytometry and IHC in lymph nodes of lymphomas has been reported as $88 \%$ [18]. Flow cytometry has better sensitivity than IHC $[18,19]$.

In our study, 18 of 48 (37.5\%) NHL patients with BM involvement were JL1-positive. This is lower than the proportion of JL1positivity in adults with AML and ALL reported by You, et al. [20] and Park, et al. [21]; however, Park, et al. [21] detected JL1-positive cells in only $33.3 \%$ of adult AML specimens. Some characteristics - including advanced age, advanced disease stage, poor performance status, bulky disease, high lactate dehydrogenase levels, and central nervous system or BM involvement-are associated with poor outcomes in both adult and pediatric patients with NHL [20, 22, 23]. JL1 expression was significantly associated with longer OS in patients with Burkitt lymphoma [16]. In our study, all four patients with Burkitt lymphoma with BM involvement were JL1-positive. JL1 expression in NHL was significantly associated with $\mathrm{CR}$ after chemotherapy $(P=0.004)$ and lower levels of BM involvement at follow-up ( $P=0.017)$; however, it was not associated with OS $(P=0.557)$.

The functional significance of $\mathrm{JL} 1$ expression in NHL is unclear because the molecule that reacts with the anti-JL1 antibody has yet to be identified. JL1 can induce homotypic adhesion of immature thymocytes in vitro, a reaction mediated by the interaction of lymphocyte function-associated antigen 1 and intercellular adhesion molecule 1 , and cytoskeletal reorganization [24]. These findings indicate that JL1 may be involved in the migration or metastasis of lymphoma and thus may present a new target for immunotherapy. The limitations of this study were small number of patients and heterogenous subtypes of $\mathrm{NHL}$.

In conclusion, JL1 expression on BM lymphoma cells was de- tected in $37.5 \%$ of patients with NHL with BM involvement. The JL1-positive rate was particularly high in Burkitt lymphoma, and JL1-positivity was significantly associated with superior CR and lower rates of BM involvement in patients with $\mathrm{NHL}$ after chemotherapy. Therapy targeting the JL1 antigen of lymphoma cells might not be necessary, because JL1-positive NHL patients showed better outcomes.

\section{Authors' Contributions}

CJP and CWS conceived, initiated, and designed the study and coordinated the drafting of the manuscript. MSK and CJP performed the bone marrow examination. MSK and CJP carried out data analysis and wrote the manuscript. MSK, YUC, SSJ, EJS, CSP, and JH were responsible for data collection and reviewing the medical charts and assisted in performing statistical analyses. HJI, JJS, and DHY supervised the study design, reviewed and commented on the manuscript, and approved the final draft. All authors read and approved the final manuscript.

\section{Conflicts of Interest}

None declared.

\section{Research Funding}

None declared.

\section{ORCID}

Min-Sun Kim Chan-Jeoung Park

Young-Uk Cho

Seongsoo Jang

Eul-Ju Seo

Chan-Sik Park

Jooryung Huh

Ho Joon Im

Jong Jin Seo

Dok Hyun Yoon

Cheolwon Suh

https://orcid.org/0000-0003-2061-5726

https://orcid.org/0000-0003-4396-8348

https://orcid.org/0000-0002-4403-8989

https://orcid.org/0000-0002-0045-1747

https://orcid.org/0000-0002-8247-3746

https://orcid.org/0000-0001-9783-4498

https://orcid.org/0000-0002-2148-5778

https://orcid.org/0000-0001-8799-4068

https://orcid.org/0000-0002-0191-7836

https://orcid.org/0000-0002-8289-3548

https://orcid.org/0000-0002-9178-4431

\section{REFERENCES}

1. Park CS and Park SH. Diagnostic usefulness of monoclonal antibody for T lymphoblastic lymphoma/acute lymphoblastic leukemia-specific JL1 
antigen in paraffin embedded tissue. Korean J Pathol Trans Med 1999; 33:1033-8.

2. Shin YK, Choi EY, Kim SH, Chung J, Chung DH, Park WS, et al. Expression of leukemia-associated antigen, JL1, in bone marrow and thymus. Am J Pathol 2001;158:1473-80.

3. Park SH, Bae YM, Kwon HJ, Kim TJ, Kim J, Lee SJ, et al. JL1, a novel differentiation antigen of human cortical thymocyte. J Exp Med 1993; 178:1447-51.

4. Chung JK, So Y, Hong MK, Choi SR, Jeong JM, Lee DS, et al. In vitro and in vivo properties of murine monoclonal antibody for a novel immature thymocyte-differentiated antigen, JL1. Nucl Med Biol 1997;24:433-7.

5. Park WS, Bae YM, Chung DH, Kim TJ, Choi EY, Chung JK, et al. A cell surface molecule, JL1; a specific target for diagnosis and treatment of leukemias. Leukemia 1998;12:1583-90.

6. Kim S, Hong JW, Cho WD, Moon YR, Yoon SS, Kim MY, et al. Characterization of two novel mAbs recognizing different epitopes on CD43. Immune Netw 2014;14:164-70.

7. Kim TJ and Park SH. Immunotherapeutic potential of JL1, a thymocyte surface protein, for leukemia. J Korean Med Sci 1998;13:455-8.

8. Chung J, Park S, Kim D, Rhim J, Kim I, Choi I, et al. Identification of antigenic peptide recognized by the anti-JL1 leukemia-specific monoclonal antibody from combinatorial peptide phage display libraries. J Cancer Res Clin Oncol 2002;128:641-9.

9. Park YS, Park SH, Park SJ, Kim Y, Jang KT, Ko YH, et al. Expression of JL1 is an effective adjunctive marker of leukemia cutis. Arch Pathol Lab Med 2010;134:95-102.

10. Shin YK, Choi YL, Choi EY, Kim MK, Kook MC, Chung J, et al. Targeted cytotoxic effect of anti-JL1 immunotoxin against a human leukemic cell line and its clinical implications. Cancer Immunol Immunother 2003;52: 506-12.

11. Hwang I, Go H, Jeon YK, Ko YH, Yoon DH, Suh C, et al. Expression of JL1 in Burkitt lymphoma is associated with improved overall survival. Virchows Arch 2011;459:353-9.

12. Swerdlow SH, Campo E, Pileri SA, Harris NL, Stein H, Siebert R, et al. The 2016 revision of the World Health Organization classification of lymphoid neoplasms. Blood 2016;127:2375-90.

13. Oken MM, Creech RH, Tormey DC, Horton J, Davis TE, McFadden ET, et al. Toxicity and response criteria of the Eastern Cooperative Oncology
Group. Am J Clin Oncol 1982;5:649-55.

14. Dunleavy K, Pittaluga S, Maeda LS, Advani R, Chen CC, Hessler J, et al. Dose-adjusted EPOCH-rituximab therapy in primary mediastinal B-cell lymphoma. N Engl J Med 2013;368:1408-16.

15. Freedman AS, Jacobson CA, Mauch P, Aster JC. Non-Hodgkin's lymphoma. In: DeVita VT, Lawrence TSR, et al., eds. DeVita, Hellman, and Rosenberg's cancer: principles and practice of oncology. 10th ed. Philadelphia, PA: Lippincott Williams \& Wilkins, 2015:1552-87.

16. Zelenetz AD, Gordon LI, Wierda WG, Abramson JS, Advani RH, Andreadis CB, et al. Non-Hodgkin's lymphomas, version 4.2014. J Natl Compr Canc Netw 2014;12:1282-303.

17. Horwitz SM, Zelenetz AD, Gordon LI, Wierda WG, Abramson JS, Advani $\mathrm{RH}$, et al. NCCN Guidelines Insights: Non-Hodgkin's Lymphomas, Version 3.2016. J Natl Compr Canc Netw 2016;14:1067-79.

18. El-Sayed AM, El-Borai MH, Bahnassy AA, El-Gerzawi SM. Flow cytometric immunophenotyping $(\mathrm{FCl})$ of lymphoma: correlation with histopathology and immunohistochemistry. Diagn Pathol 2008;3:43.

19. Gruss HJ and Herrmann F. CD3O ligand, a member of the TNF ligand superfamily, with growth and activation control CD30+ lymphoid and lymphoma cells. Leuk Lymphoma 1996;20:397-409.

20. You E, Kim S, Park CJ, Jang S, Cho YU, Yoon CH, et al. JL1 antigen expression of leukemic cells in childhood acute leukemia. Haematologica 2017;102:353.

21. Park HS, Lee JH, Lee JH, Kim DY, Choi EJ, Hur EH, et al. Expression of JL1 antigen in acute leukemia and myelodysplastic syndrome. Blood 2015; 126:3826.

22. Patte C, Auperin A, Michon J, Behrendt H, Leverger G, Frappaz D, et al. The Société Française d'Oncologie Pédiatrique LMB89 protocol: highly effective multiagent chemotherapy tailored to the tumor burden and initial response in 561 unselected children with B-cell lymphomas and L3 leukemia. Blood 2001;97:3370-9.

23. Zhao X, Pogue S, Lin J, Bi M, Wilson Dand Hsi ED. JL1 is a cell surface molecule of acute leukemia blasts: potential for targeted immunotherapy. Cancer Res 2012;72:2525.

24. Lee GK, Jung KC, Park WS, Kook MC, Park CS, Sohn HW, et al. LFA-1and ICAM-1-dependent homotypic aggregation of human thymocytes induced by JL1 engagement. Mol Cells 1999;9:662-7. 